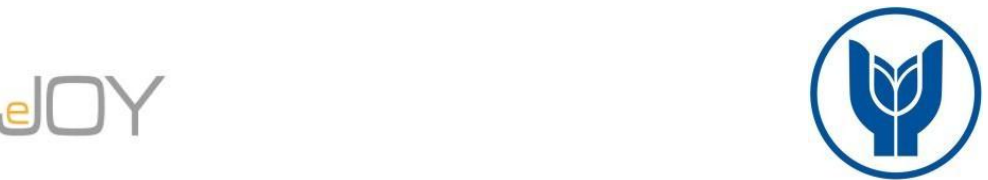

Kızıl, B., C., Ceylan, R. Journal of Yasar University, 2018, 13/50, 197-209

\title{
Sağlık Harcamalarının Ekonomik Büyüme Üzerine Etkisi: Türkiye Örneği
}

\section{The Impact of Health Expenditures on Economic Growth: The Sample of Turkey}

\author{
Barış Can KIZIL, Türkiye, bariscankizil@gmail.com \\ Reşat CEYLAN, Pamukkale Üniversitesi, Türkiye, rceylan@pau.edu.tr
}

\begin{abstract}
Öz: Bu çalı̧̧manın amacı, Türkiye'de $1979-2015$ periyodu boyunca sağlık harcamalarl ve 65 yaş üzeri nüfusun ekonomik büyüme üzerine etkisini ARDL yaklașımı ve FMOLS, DOLS ve CCR tahmin yöntemlerini kullanarak incelemektir. Çalışmada, beşeri sermaye birikimi ile sağlık harcamalarını ilişkilendirmek için içsel büyüme modeli kullanılmaktadır. Ampirik sonuçlar, kişi başı sağlık harcamaları ile ekonomik büyüme arasında pozitif ve istatiksel olarak anlamlı bir ilişkinin olduğunu göstermektedir. Ancak, 65 yaş üzeri nüfusun kişi başı gelir üzerindeki etkisine ilişkin ampirik sonuçlar, yöntemler itibari ile farklıllk göstermektedir.
\end{abstract}

Anahtar Kelimeler: Sağlık Harcamaları, Ekonomik Büyüme, Beșeri Sermaye, ARDL Sınır Testi, Türkiye

Abstract: The aim of the study is to investigate the effect of health expenditure and population over 65 years on economic growth in Turkey by using ARDL approach and estimation methods of FMOLS, DOLS and CCR over the periods of 1979-2015. In the study, endogenous growth model is used in order to relate human capital accumulation and health expenditure. Empirical results show that there are positive and statistically significant relations between per capita health expenditure and economic growth. However, emprical findings related to the effect of population over 65 years on per capita income do not seem to support similar results.

Keywords: Health expenditures, Economic growth, Human capital, ARDL Bound Test, Turkey

\section{Giriş}

Geçmişten günümüze yaşanan ekonomik ve sosyal evrimsel süreçte, bireylerin daha özgür düşünüp hareket edebildiği ve demokrasi kavramının ülkelerin kültürlerine giderek daha fazla yerleştiği görülmektedir. Bununla birlikte, insan hakları, adalet duygusu, kişisel güvenlik, mal edinme ve miras bırakma gibi değisşen kültürün beraberinde getirdiği yeni kavramlar ülkeleri sosyal devlet yönetim anlayışına itmektedir. Bu anlayış, ülkelerin ekonomik kalkınma hedeflerinin oluşturmasına ve bu konuda çalışmalarını da beraberinde getirmektedir. Çünkü ekonomik refaha ulaşmanın yolu öncelikle ekonomik kalkınma ile başlamaktadır. Diğer bir ifadeyle ekonomik kalkınmayla ülkelerin sahip olduğu içsel dinamiklerin (fiziki ve beşeri sermaye) kalitesinin artması sayesinde ekonomik büyüme sağlanmaktadır. Burada, ekonomik büyüme ile ülkelerin gayri safi yurt içi hasılalarının artışından bahsedilmektedir. $\mathrm{Bu}$ artış, ülkenin gelirini doğrudan etkilemesi bakımından refah düzeyinin bir göstergesi olarak kabul edilmektedir.

Ekonomik kalkınma ile birlikte, sosyal refahın gelişmesi ve bunun sonucunda da dünya nüfusunun artması kaçınılmaz olmuştur. Bununla birlikte, artan nüfus üretim artışını da beraberinde getirmiştir.Işste bu noktada, üretim artışıın nasıl bu kadar hızlı gerçekleşebildiği ve dünyanın daha fazla nüfusu besleyebilir hale geldiği; gelecekte nüfus artışı ve bu artışı besleyecek üretim artışının hangi dinamiklerin etkisi altında gerçekleşeceği soruları, İçsel Büyüme Teorileri'nin [Endogenous Growth Theories] ortaya atılmasına ve bu konu üzerinde devinimsel çalışmalara yol açmıştır (Keskin, 2011: 126).Neoklasik Solow-Swan modelinin beşeri sermaye ile genişletilmiş versiyonu olan Mankiw, Romer ve Weil (1992) modeli, bu çalışmaların temelinde uzun dönemde ekonomik büyümenin sağlanması için fiziki sermayenin yanı sıra beşeri sermayenin de üretim fonksiyonunda yer alması gerektiğini ileri sürmüştür.

Beşeri sermaye, tanım gereği, bireylerin yaşamları boyu edindikleri bilgilerin, becerilerin ve tecrübelerinin tümü şeklinde ifade edilmektedir. Fakat, kavrama daha geniş kapsamlı bakıldığında beşeri sermaye, toplumdaki bireylerin üretim süreçleri ile ilgili olarak bir yandan sahip oldukları bilgilerinin, becerilerinin, yeteneklerinin ve tecrübelerinin, işine olan duygusal bağlılı̆ının, davranışlarının ve değerlerinin ulaştığı düzeyi; diğer yandan bedensel ve zihinsel zindeliğini ya da sağlamlığını ifade eden bir kavram olarak tanımlanmaktadır (Keskin, 2011: 128).Buna göre, bireylerin nitelikli eğitimlerinin yanı sıra sağlıklı olmaları da beşeri sermaye kavramı açısından önem arz etmektedir. Dünya Sağlık Örgütü'nün yaptığı sağlık tanımına göre sağlık, fiziksel ve zihinsel olarak optimum olma durumunu ifade etmektedir. Diğer yandan Lustig (2006), sağlığı sadece bireyin ruhsal veya fiziksel hastalığının olmaması olarak değil, aynı zamanda hayatı boyunca kendine özgü beşeri niteliğini oluşturma biçiminde tanımlamaktadır. Bu anlamda Lustig (2006), sağlığın içsel bir değişken olduğunu ve bireyler için araçsal bir değer ifade ettiğinin altını çizmektedir. Burada araçsal değer olarak ifade edilen kavram özünde, sağlığın ekonomik büyümeyi dolaylı yollardan etkilemesi şeklinde ifade edilmektedir. 
Sağlık ve eğitim beşeri sermayenin en temel bileşenleridir. Literatürde daha önce büyüme ile beşeri sermaye ilişkisini irdeleyen çalışmalarda, eğitim yönüne daha çok odaklanıldığı, fakat sağlık vurgusunun yeteri kadar yapılmadığı görülmektedir. Araştırmacılar, bu konu hakkında farklı görüşlere sahip olsalar da, sağlı̆̆ın nüfus, gelir, refah ve beşeri sermaye faktörlerinin oluşumunda eğitim kadar önemli bir kavram olduğunu kabul etmektedirler. Nitekim Bloom ve diğ. (2001), beşeri sermayenin yalnızca bireysel yetenekler olarak düşünülmemesi gerektiğini, ayrıca sağlığın tüm bunları elde edebilmek için bir ön koşul niteliği taşıdığını ifade etmektedir. Yazarlar, sağlığı ekonomik büyümenin temel dinamiklerinden biri olarak görmektedirler.

Bir toplumun sağlık düzeyi ile ekonomik gelişmişliği arasında yakın bir ilişki bulunmaktadır. Bu açıdan bakıldığında, bireylerin yapmış olduğu sağlı harcamaları ve ülkelerin sağlık yatırımları için gayrisafi yurt içi hasılalarından ne kadar kaynak ayırdıkları gelişmişlik seviyelerini göstermektedir. Barro (1996), sağlığ ekonominin motoru olarak görmüş ve sermaye üreten bir varlık olarak nitelendirmiştir. Bu hususta, sağlığa yapılan yatırım ile bir üretim faktörü niteliğinde olan beşeri sermayenin artırılması amaçlanmaktadır. Yapılan ampirik çalışmalar, beşeri sermayenin ülke kalkınmasına uzun dönemde pozitif katkı sağladığını göstermektedir.

$\mathrm{Bu}$ çalışmanın amacı, ekonomik büyüme ile sağlık harcamaları arasındaki ilişkiyi kısa ve uzun dönemde incelemektir. Literatürde bu ilişkiyi konu edinmiş daha önceki çalışmalarda kullanılan belli başlı sağlık değişkenleri;sağlı harcamalarının gayri safi yurt içi hasıla içindeki payı, yaşam beklenti süresi, doğum oranı, ölüm oranı, nüfus artış hızı, kişi başı sağlık harcamaları, kamu sağlık harcamaları şeklinde sıralanabilmektedir (Yumuşak ve Yıldırım, 2009; Yardımcıŏglu, 2012; Çalışkan ve diğ., 2013; Selim ve diğ., 2014). Fakat bu çalışmada, sağlık harcamaları ile büyüme ilişkisi demografik yönden de ele alınmaktadır. Bu bakımdan, model kişi başı gayri safi yurt içi hasıla ve kişi başı sağlık harcamalarına ek olarak 65 yaş üzeri nüfusun toplam nüfusa oranı dahil edilerek oluşturulmuştur. Burada yaşlı nüfusun değişken olarak kullanılmasının sebebi toplumdaki en çok sağlık harcaması yapılan grubu temsil etmesidir. Bu anlamda, nüfusun giderek yaşlanmasının sağlık harcamalarını artırması ve doğrudan ekonomik büyümeyi pozitif etkilemesi beklenmektedir. Diğer yandan, nüfusun yaşlanmasının, diğer bir ifadeyle, toplam nüfus içerisinde yaşlı nüfusun payının artmasının, toplumların aile planlamasına önem verdiğini, daha çok gelişmiş ülkelerde görülen bu planlı nüfus yapısının beşeri sermayenin niteliğini belirlediğinin bilindiği ve gelişmekte olan ülkeler kategorisinde olan Türkiye'de de bu bilincin arttığını göstermektedir.

Çalışmanın bundan sonraki kısımları şu şekilde organize edilmektedir. Devam eden bölümde, teorik literatür ile birlikte daha önce yapılan benzer çalışmaların yer aldığı ampirik literatürden bahsedilmektedir. Üçüncü bölümde, çalışmada kullanılacak olan veri seti açıklanmakta ve ekonometrik model tanımlanmaktadır. Dördüncü bölümde ekonometrik metodoloji anlatılmaktadır. Beşinci bölümde, elde edilen ampirik bulgular gösterilmektir. Altıncı ve son bölümde, çalışmadan elde edilen sonuçlar ve politika önerileri sunulmaktadır.

\section{Literatür Taraması}

Ülkelerin sahip oldukları üretim kaynaklarını optimum bir bileşenle etkin kullanması, üretimi destekleyen politikaların belirlenmesi ve tüm bunların sürdürebilirliğinin sağlanması konuları ekonomik büyüme alanının temel araştırma alanını belirlemektedir.

Bu alanda 1980'li y1llara kadar Neo klasik düşünce söz sahibi olmuştur. Neo klasik model, büyümenin teknolojiyle mümkün olabileceğini ileri sürmüştür. Fakat teknolojinin “cennetten gelen bir nimet” şeklinde kabul edilmesi, diğer bir ifadeyle dişsal bir değişken olarak tanımlanmasından dolayı tam anlamıyla büyümenin nasıl gerçekleşebildiğini açıklamada yetersiz kalmıştır. $\mathrm{Bu}$ nedenle, büyümenin kaynaklarının neler olduğu araştırmacılar tarafindan her zaman bir tartışma konusu olmuştur. İlerleyen yıllarda, Romer (1986) ve Lucas'ın (1988) yapmış oldukları çalışmalar ışığında içsel büyüme teorisinin temelleri atılmıştır. Ülkelerin büyüme kaynaklarının belirlenmesi ve Neo klasik görüşün dışsal faktör kabul ettiği teknolojinin içselleştirilmesi konusunda çalışmalar yapmışlardır. Yeni geliştirilen modellerle, teknolojinin yanı sıra beşeri sermayenin, dış ticaretin, finansal derinliğin ve kamu harcamalarının da ekonomik büyümeyi etkileyen yeni birer faktör olabileceği ileri sürülmüştür.

Büyüme teorileri genel olarak, ülkeler arasındaki büyüme farklılıkları ve uzun dönem büyüme dengesinin sağlanmasını iki faktör ile açıklamaya çalışır: bilgi birikiminin düzeyi ve beşeri sermaye. Schultz (1961) ve Becker (1962)'in beşeri sermaye modellerinde ve Lucas (1988), Romer (1990) ve Rebelo (1991)'nun içsel büyüme modellerinde, bilgi, üretim sürecinde merkezi bir role sahip olmuştur (Jaoul, 2004). Bilgi birikimi, yaparak öğrenme sürecinin ya da Ar-Ge yatırımlarının sonucu olarak ortaya çıkmıştır (Yanıkkaya, 2002). Dolayısıyla, beşeri sermaye yatırımları kapsamında AR-GE harcamalarının artırılması veya etkinleştirilmesi, fiziki yatırımlarda bir artışa neden olmuş ve yüksek bir reel büyüme trendine ulaşılmasına olanak tanımıştır. (Çoban, 2003: 172).

Diğer yandan, Lucas (1988) beşeri sermayenin uzun dönemde ekonomik büyümeye katkısının potansiyel çıktı düzeyine bağlı olduğunu ve aralarında doğrusal bir ilişkinin varlığına dikkat çekmiştir.Bu anlamda, büyümenin sürdürülebilir olması beşeri sermaye artışı ile sağlanmaktadır. Lucas (1988), Cobb-Douglas tipi üretim fonksiyonunu temel alıp fonksiyona beşeri sermayeyi de dahil ederek fonksiyonu yeniden türetmektedir. Bu anlamda, çalışma zamanının artması ve çalışanların potansiyel yeteneklerini ortaya çıkarabilme kabiliyetinin artması üretimin de dolaylı olarak artması anlamına gelmektedir. Sonuç olarak Lucas (1988) ülkelerin yapmış 
oldukları eğitim, ar-ge ve sağlık yatırımlarının bireylerin bilgi birikimi ve verimliliklerini olumlu yönde etkileyeceğinden büyümeye fiziki sermayeye yapılan yatırımlardan daha fazla etkisinin olabileceğini ileri sürmektedir.

Beşeri sermayenin, içsel büyüme teorileri açısından önemli olması farklı bir modelin gelişmesine de katkı sunmuştur. Bu modele göre, nüfus artışı ve beşeri sermaye birikimi modelin karar değişkenidir. Farklı bir deyişle, beşeri sermaye büyümenin motoru olarak görülmüştür. Bu modelin ilk temsilcileri olarak Tamura, ve diğg. (1990) yapmış oldukları çalışmada, doğurganlık oranını içsel bir değişken olarak tanımlamış ve bu oranın artması beşeri sermaye stokunu artıracağından getirisinin de artacağını varsaymışlardır. Doğurganlık oranı, fiyatlara ve gelir düzeyine bağlı olarak değişen ekonomik bir karardır (Ercan,2000). Diğer yandan yeni bilginin üretimi de geçmiş nesillerin sağladığı beşeri sermaye birikiminin bir fonksiyonudur (Ercan, 2000). Bu açıdan bakıldığında, aile planlaması, ebeveynlerin ve özellikle annenin zamanının alternatif maliyetiyle, sağlık ve eğitim harcamalarının bir fonksiyonu olmaktadır. Bu bağlamda, sosyokültürel ve ekonomik kalkınmasını tamamlamış gelişmiş ülkeler, insana yapılan yatırımın getirisinin daha fazla olduğunu bildiklerinden, bu ülkelerde az çocuklu aile yapısının tercih edilmesi beşeri sermaye yatırımlarının niteliğini artırmaktadır. Bunun tam tersi, sosyo kültürel ve ekonomik kalkınma açısından kısır olan az gelişmiş ülkelerde, çok çocuklu aile yapılarının tercih edilmesi, çocukların eğitim, sağlık vb. gibi beşeri yatırımlardan daha az faydalanmasına neden olmaktadır. Gelişmekte olan ülkelerin ise, gelişmiş ülkelerin büyüme stratejilerini takip etmeleri, nüfuslarını daha verimli kılmaya çaba göstermelerine yol açmaktadır.

Sonuç olarak modelden iki farklı istikrarlı denge sonucu elde edilmektedir. Birincisi, büyük aile yapısı ve kıt beşeri sermaye ve ikincisi ise küçük aile yapısı ve artan beşeri sermayedir. Ülkeler yeterince şansları varsa ve beşeri sermayeye yatırım yaparlarsa, Malthus Dengesi’nden kalkınma dengesine geçebilirler (Becker ve diğ., 1990). Şans faktörü bir yana bırakılırsa bu model, eğitim ve sağlık politikalarının, beşeri sermayeye ilişkin yatırımlarla, beşeri ve fiziki sermaye bağlantısı üzerindeki hayati önemini ortaya koymaktadır (Ercan, 2000).

Beşeri sermayenin büyüme üzerindeki etkisi, ampirik olarak pek çok kere ele alınmıştır. Bu minvalde, sağlık odaklı içsel büyüme teorisi temelli yapılan çalışmalarda, sağlığın uzun ve kısa dönemde ekonomik büyüme üzerindeki etkisi çalışma yapılan ülke açısından farklılık gösterebilmektedir. Diğer bir ifadeyle, ülkelerin gelişmişlik seviyeleri ve buna bağlı olarak sağlığa verdikleri önem bu farklılığın oluşmasında temel neden olabilmektedir. Fakat, bunun dışında iktisatçıların da kullandıkları farklı ekonometrik yöntemler ve modelde tercih edilen sağlık değişkenlerinin farklılık arz etmesi sağlığın hasıla üzerindeki etkisinin de farklı olacağı doğal sonucunu doğurmaktadır.

Literatüre bütünüyle bakıldığında, Türkiye'de ve dünya genelinde sağlığın ekonomik büyümeye katkısının pozitif etkisinin daha fazla olduğu Tablo 1'den anlaşılmaktadır.

Tablo 1. Ampirik Literatür Özeti

\begin{tabular}{|c|c|c|c|c|}
\hline Yazar Adı & Dönem & Ülke & Metodoloji & $\begin{array}{l}\text { Ampirik } \\
\text { Bulgular }\end{array}$ \\
\hline Taban (2006) & $1968-2003$ & Türkiye & $\begin{array}{l}\text { Nedensellik ve Eş } \\
\text { bütünleşme Analizi }\end{array}$ & $+=+$ \\
\hline $\begin{array}{l}\text { Yumuşak \& } \\
\text { Yildırım } \\
\text { (2009) }\end{array}$ & $1980-2005$ & Türkiye & $\begin{array}{c}\text { Eş bütünleşme } \\
\text { Testi ve } \\
\text { Nedensellik } \\
\text { Analizi } \\
\end{array}$ & + \\
\hline $\begin{array}{c}\text { Bakare \& } \\
\text { Olubokun } \\
(2011)\end{array}$ & $1970-2008$ & Nijerya & EKK & + \\
\hline $\begin{array}{l}\text { Yardımcioğlu } \\
\quad(2012)\end{array}$ & $1975-2008$ & $\begin{array}{l}25 \text { OECD } \\
\text { Ülkesi }\end{array}$ & Panel Veri & $+=+$ \\
\hline $\begin{array}{c}\text { Nasiru \& } \\
\text { Usman (2012) }\end{array}$ & $1980-2010$ & Nijerya & $\begin{array}{l}\text { Eş bütünleşme } \\
\text { Analizi }\end{array}$ & $+=+$ \\
\hline $\begin{array}{c}\text { Ay \& } \\
\text { Kızılkaya \& } \\
\text { Koçak } \\
(2013) \\
\end{array}$ & $1968-2006$ & Türkiye & $\begin{array}{l}\text { Eş bütünleşme } \\
\text { Analizi }\end{array}$ & + \\
\hline $\begin{array}{c}\text { Aydemir \& } \\
\text { Baylan (2015) }\end{array}$ & 1998-2012 & Türkiye & $\begin{array}{l}\text { Nedensellik ve Eş } \\
\text { bütünleşme Analizi }\end{array}$ & + \\
\hline $\begin{array}{c}\text { Okunade } \\
\text { \&Murthy } \\
(2016)\end{array}$ & $1960-2012$ & $\mathrm{ABD}$ & $\begin{array}{l}\text { Eş bütünleşme } \\
\text { Analizi }\end{array}$ & + \\
\hline $\begin{array}{l}\text { Mehmood \& } \\
\text { Raza \& } \\
\text { Mureed } \\
(2014) \\
\end{array}$ & $1990-2012$ & 26 Asya Ülkesi & PMG & $+=+$ \\
\hline
\end{tabular}




\begin{tabular}{|c|c|c|c|c|}
\hline $\begin{array}{l}\text { Gerdtham \& } \\
\text { Löthgren } \\
(2000)\end{array}$ & 1960-1997 & $\begin{array}{l}21 \text { OECD } \\
\text { Ülkesi }\end{array}$ & Panel Veri & + \\
\hline $\begin{array}{c}\text { Atılgan \& } \\
\text { Kılış \& } \\
\text { Ertuğrul } \\
(2016)\end{array}$ & $1975-2013$ & Türkiye & $\begin{array}{l}\text { Eş bütünleşme } \\
\text { Analizi ve Kalman } \\
\text { Filtre Modeli }\end{array}$ & + \\
\hline $\begin{array}{c}\text { Çetin \& } \\
\text { Ecevit (2010) }\end{array}$ & $1990-2006$ & $\begin{array}{l}15 \text { OECD } \\
\text { Ülkesi }\end{array}$ & Panel Veri & - \\
\hline $\begin{array}{c}\text { Selim \& } \\
\text { Uysal \& } \\
\text { Eryiğit (2014) }\end{array}$ & 2001-2011 & $\begin{array}{l}27 \text { AB Ülkesi } \\
\text { ve Türkiye }\end{array}$ & $\begin{array}{c}\text { Eş bütünleşme ve } \\
\text { Hata Düzeltme } \\
\text { Modeli }\end{array}$ & + \\
\hline $\begin{array}{c}\text { Şimşir \& } \\
\text { Çondur \& } \\
\text { Bölükbaş \& } \\
\text { Alataş (2015) }\end{array}$ & $1975-2012$ & Türkiye & $\begin{array}{l}\text { Eş Bütünleşme } \\
\text { Analizi }\end{array}$ & - \\
\hline Akar (2014) & $\begin{array}{c}\text { Ocak 2004-Mart } \\
2013\end{array}$ & Türkiye & $\begin{array}{c}\text { Eş Bütünleşme } \\
\text { Analizi ve Vektör } \\
\text { Hata Düzeltme } \\
\text { Modeli }\end{array}$ & + \\
\hline
\end{tabular}

Buna göre, Taban (2006), Yardımcıŏlu (2012), Nasiru ve Usman (2012), ve Mehmood ve diğ. (2014), yapmış oldukları çalışmalarında, seçilen sağlık değişkenlerinin birbirinden farklı olmasına karşın, uzun dönemde elde ettikleri sonuçlar benzerlik taşımaktadır. Bu anlamda, ampirik bulgular, sağlık harcamalarından hasılaya doğru ve hasıladan sağlık harcamalarına doğru çift yönlü nedensellik ilişkisini göstermektedir. Ayrıca, eş bütünleşme testlerinde, ele alınan ülkelerin yine uzun dönemde sağlık harcamaları ile ekonomik büyüme arasında eş bütünleşik bir ilişkinin varlığını içermektedir. Yukarıda da bahsedildiği gibi, literatürde yer alan çalışmaların büyük bir kısmı (Yumuşak ve diğ (2009), Bakare ve diğ. (2011), Okunade ve diğ. (2016), Atılgan ve diğ. (2016)), sağl1k harcamalarının ekonomik büyümeye katkısının pozitif yönde etkilediği sonucunu vermektedir. Ancak, Çetin ve Ecevit (2010) 15 OECD ülkesinin yer aldığı, Havuzlanmış Regresyon modeli kapsamında OLS panel veri çalışmasında ve Şimşir ve diğ . (2015) Türkiye için yaptıkları ARDL eş bütünleşme analizinde bu ilişkiyi negatif olarak elde etmişlerdir. Ekonometrik olarak değerlendirildiğinde, tercih edilen yöntem veya seçilen sağlık değişkenlerinin çalışmayı bu sonuca taşıdığını ortaya koymaktadır.

\section{Model ve Veri Seti}

Çalışmanın amacı, Türkiye'de kişi başı sağlık harcamalarının ekonomik büyüme üzerindeki etkisini incelemektir. $\mathrm{Bu}$ amaçla, aşağıdaki regresyon denkleminden hareket edilmektedir:

$$
L N G D P P C=\beta_{0}+\beta_{1} L N K S B S H+\beta_{2} L N P O P+\mu_{t}
$$

Burada; $L N G D P P C$ : Kişi başına düşen reel GSYIH, $L N K S B S H$ : Kişi başına düşen kamu sağlık harcamaları, LNPOP:65 Yaş üstü nüfusun toplam nüfusa oranı, $\beta_{0}, \beta_{1}$ ve $\beta_{2}$ tahmin edilecek parametre değerleri ve $\mu_{t}$ : ortalaması sıfir ve varyansı sabit olan hata terimidir. Verilerin tamamı hem veri setindeki çarpıklığı azaltmak hem de örneklem ölçeğini küçültmek amacıyla logaritmik forma dönüştürülmüştür. Ayrıca değişkenlerin logaritmik formda ele alınmasıyla tahmin edilen katsayı değerleri esneklik olarak yorumlanabilmektedir. Türkiye'de 1980'li yıllardan beri süregelen nüfus yapısındaki değişimi yansıtması ve yapılan birçok sağlık reformlarını kapsaması bakımından analiz dönemi 1979-2015 olacak şekilde yıllık veriler kullanılarak belirlenmiştir. Modelde bağımlı değişken kişi başına düşen reel GSYIH olup, bağımsız değişkenler sırasıyla, kişi başı sağlı harcamaları ve 65 yaş üzeri nüfusun toplam nüfus içerisindeki payı şeklinde tanımlanmıştır. Ekonomik büyümenin göstergesi olarak kullanılan kişi başına düşen reel GSYIH ve beşeri sermayenin göstergesi olarak kullanılan 65 yaş üzeri nüfusun toplam nüfus içerisindeki payı verileri Dünya Bankası (World Bank) veri tabanından alınmıştır. Diğer yandan, sağlk harcamalarının bir göstergesi olarak, kişi başı düşen sağlık harcaması modelde yer almaktadır. Bu veri kamu kişi başına düşen sağlık harcaması verisi biçiminde OECD veri tabanından alınmıştır. Literatürdeki benzer çalışmalardan farklı olarak, 65 yaş üzeri nüfusun toplam nüfusa oranı değişkeni modele dahil edilmiş ve bu değişkenin sağlık harcamaları yolu ile ekonomik büyümeye kısa ve uzun dönemde nasıl etki edeceği tahmin edilmeye çalışılmıştır.

\subsection{Tanımlayıcı İstatistikler}

Modelde yer alan değişkenlere ait tanımlayıcı istatistikler Tablo 2'de belirtilmiştir. Değişkenlerin ortalama değerlerinin tahmini, beklenen sonuca uygun görülmektedir. Bununla birlikte değişkenlerin medyan değerleri de ortalama değerlerinden çok farklı görülmemekte ve modele uygun bulunmaktadır. Fakat kişi başı sağlık harcamasının standart sapması diğer iki değişkene nispeten daha yüksek bulunması bu değişkenin yıldan yıla dalgalı seyre sahip olduğunu göstermektedir. Diğer yandan değişkenlerin basıklık ve çarpıklık katsayıları normal 
kabul edilen değer aralığında görülmektedir. Son olarak, değişkenlerin istatiksel özellikleri yapılacak olan analize uygun görünmektedir.

Tablo. 2 Tanımlayıcı İstatistikler

\begin{tabular}{|l|c|c|c|}
\hline & Kişi Başı GSYİH & Kişi Başı S.H & 65 Yaş Ü. / Top.Nüf. \\
\hline Ortalama & 8.2057 & 4.9839 & 1.7147 \\
\hline Standart Sapma & 0.7286 & 1.3518 & 0.1905 \\
\hline Maksimum Değer & 9.2873 & 6.7106 & 2.0200 \\
\hline Minimum Değer & 7.1278 & 2.2126 & 1.4787 \\
\hline Medyan & 8.0530 & 5.1856 & 1.7009 \\
\hline Basıklık & 1.6860 & 2.0476 & 1.4359 \\
\hline Çarpıklık & 0.1762 & -0.4685 & 0.1542 \\
\hline
\end{tabular}

\section{Metodoloji}

\subsection{Birim Kök Testleri}

ARDL eş-bütünleşme testi yapılırken ilk olarak serilerin durağanlıklarına bakılmalıdır. Bu bağlamda, modelde kullanılacak serilerine birim kök testi yapılması gerekmektedir. Çalışmada Augmented-Dickey Fuller (ADF), Phillips-Perron (PP) ve Kwiatkowski-Phillps-Schmidt-Shin (KPSS) birim kök testleri kullanılarak seriler sınanmaktadır. Serilerin düzeyde ve birinci farkta durağan olup olmadıkları test edilmektedir. ADF, PP ve KPSS ile test edilen serilerin durağanlık sonuçları Tablo 3'de gösterilmektedir.

Tablo. 3 ADF, PP ve KPSS Birim Kök Test Sonuçları

\begin{tabular}{|c|c|c|c|c|}
\hline \multirow{2}{*}{ Değişkenler } & \multicolumn{2}{|c|}{ ADF (DÜZEY) } & \multicolumn{2}{|c|}{ ADF (1.FARK) } \\
\hline & Sabit & Trend & Sabit & Trend \\
\hline $\operatorname{LnGDPPC}$ & -0.2871 & $-3.5939 * *$ & $-6.3079 * * *$ & $-6.1457 * * *$ \\
\hline $\operatorname{LnKSBSH}$ & -1.1827 & -1.2611 & $-9.1705^{* * * *}$ & $-9.1556 * * *$ \\
\hline $\operatorname{LnPOP}$ & 0.3409 & $-4.5130 * * *$ & $-3.5444 * *$ & $-3.3956^{*}$ \\
\hline \multirow{2}{*}{ Değişkenler } & \multicolumn{2}{|c|}{ PP (DÜZEY) } & \multicolumn{2}{|c|}{ PP (1.FARK) } \\
\hline & Sabit & Trend & Sabit & Trend \\
\hline LnGDPPC & -0.3064 & $-3.6082^{* *}$ & $-6.3079^{* * *}$ & $-6.1457^{* * * *}$ \\
\hline LnKSBSH & -1.8425 & -2.4527 & $-10.0605 \%$ & $-17.3908^{* * * *}$ \\
\hline $\operatorname{LnPOP}$ & 0.5937 & -2.8582 & -1.3197 & -1.3797 \\
\hline \multirow{2}{*}{ Değișkenler } & \multicolumn{2}{|c|}{ KPSS (DÜZEY) } & \multicolumn{2}{|c|}{ KPSS (1.FARK) } \\
\hline & Sabit & Trend & Sabit & Trend \\
\hline $\operatorname{LnGDPPC}$ & 0.6776 & 0.0965 & $0.1460^{* * *}$ & $0.1114^{* * * *}$ \\
\hline LnKSBSH & 0.7069 & 0.1896 & $0.3022^{* * * *}$ & $0.2012^{* * * *}$ \\
\hline LnPOP & 0.6783 & 0.1385 & $0.2990^{* * *}$ & $0.1607^{* * * *}$ \\
\hline
\end{tabular}

Not: *, **ve *** ifadeleri strasıla $\% 10, \% 5$ ve \%1 anlamlılı düzeylerini ifade etmektedir. Ayrica I(0) ve I(1) sirasiyla değişkenlerin seviyede ve farkta dură̆an olduğunu göstermektedir.

Tablo incelendiğinde, ADF testine göre kişi başı yurt içi hasıla (GDPPC) I(1), kişi başı sağlık harcamaları (KSBSH) I(1) ve 65 yaş üzeri nüfusun toplam nüfusa oranı (POP) I(1) olarak elde edilmiştir. Benzer olarak KPSS testinde de kişi başı yurt içi hasıla (GDPPC) I(1), kişi başı sağlık harcamaları (KSBSH) I(1) ve 65 yaş üzeri nüfusun 
toplam nüfusa oranı (POP) I(1) olarak elde edilmiştir. Ancak PP testine göre LnPOP değişkeni her iki seviyede de durağan görünmemektedir. LnGDPPC I(1) ve LnKSBSH I(1) ise sonucunu vermektedir.Tüm test sonuçları değerlendirildiğinde, değişkenlerin farklı düzeylerde durağan olması, ARDL tekniği açısından bir sorun teşkil etmemektedir.

\subsection{ARDL Sınır Testi Eş bütünleşme Yaklaşımı}

Eş bütünleşme testleri modeldeki değişkenler arasında uzun dönemli bir ilişkinin olup olmadığını ortaya koymak amacıyla kullanılmaktadır. Bu bağlamda, sağlık harcaması göstergeleri ve büyüme verileri arasındaki ilişkiyi inceleyen çalışmalarda sık kullanılan yöntemlerden biri de Oto-Regresif Dağıtıcı Gecikmeli Model (ARDL)'dir.

Literatürde genellikle kullanılan Engle-Granger (1987), Johansen (1988) eş-bütünleşme testleri ve Vektör Oto Regresif (VAR) modelinde, düzeyde durağan olmayan iki değişkenin durağan bir bileşiminin mümkün olabileceği savında bulunulmaktadır. Buna göre,değişkenler aynı düzeyde durağan olmalıdır. Bu durum, uygulamada büyük kısıtlar oluşturduğundan Peseran ve diğ. (2001) tarafindan önerilen ve farklı derecelerden bütünleşik değişkenler arasındaki ilişkinin elde edilmesini mümkün kılan ARDL yaklaşımı ile bu sorun giderilmiştir. ARDL modelinin avantajı, serilerin düzeyde veya birinci farkında durağan olmasının sınır testi uygulamaya engel olmamasıdır. Modelin başka bir avantajı ise kısıtsız hata düzeltme modelini kullanmasından dolayı klasik eş-bütünleşme testlerine göre istatistiksel olarak daha güvenilir sonuçlar verebilmesidir. Seriler arasında kısa ve uzun dönem durumları hakkında bilgi içermesi modelin diğer avantajıdır.

Bu çalışma ile Türkiye'de sağlık harcamalarının ekonomik büyümeyi ne yönde etkilediği sorusuna cevap aranmaktadır. Bu anlamda, belirtilen parametrelere uygun ARDL modeli ise şu şekilde tanımlanmıştır:

$\triangle L N G D P P C_{t}=\alpha+\gamma L N G D P P C_{t-1}+\sum_{i=1}^{q} \phi_{i t} \Delta L N G D P P C_{i, t-i}+\sum_{i=0}^{n} \beta_{i t} \Delta L N K S B S H_{i, t-i}+\sum_{i=0}^{p} \phi_{i t} \Delta L N P O P_{i, t-i}+\delta_{1 i} L N K S B S H_{t-i}+\delta_{2 i} L N P O P_{t-i}+\mu_{i t}$

Denklem tahmin edildikten sonra sınır testi F-istatistiği ile yapılmaktadır. Modelde kullanılan değişkenler arasında eş-bütünleşme ilişkisi olup olmadığını gösteren sıfır ve alternatif hipotezler aşağıdaki gibi oluşturulmaktadır:

$$
\begin{aligned}
& \mathrm{H}_{0}: \delta_{1}=\delta_{2}=0 \\
& \mathrm{H}_{1}: \delta_{1} \neq \delta_{2} \neq 0
\end{aligned}
$$

Eğer tanımlanan model için hesaplanan F-istatistik değeri üst sınır kritik F-istatistiğinden büyük ise eşbütünleşme ilişkisinin olmadığını ifade eden sıfır hipotezi red edilir.Böylelikle değişkenler arasında eş-bütünleşme ilişkisinin olduğu söylenebilmektedir. Eğer hesaplanan F-istatistik değeri alt sınırı kritik F-istatistiğinden küçük ise sıfır hipotezi kabul edilmektedir. Son olarak, hesaplanan F-istatistiği, üst-sınır ve alt sınır kritik F-istatistik değerleri arasında ise eş-bütünleşme ilişkisi konusunda kararsız kalınmaktadır.

Modeldeki değişkenler arasında eş-bütünleşme ilişkisinin varlığını gösteren alternatif hipotezin geçerli olması halinde, uzun dönem model tahmini 3 numaralı denklemle tanımlanmaktadır:

$$
G D P P C=\beta_{0}+\sum_{i=1}^{n} \beta_{1} K S B S H_{t-i}+\sum_{i=1}^{p} \beta_{2} P O P_{t-i}+u_{t}
$$

Değişkenler arasındaki uzun dönem ilişkilerin belirlenmesinden sonraki aşamada, hata düzeltme modeli (ECM) kullanılarak kısa dönemli ilişkilerin araştırılması olmaktadır. Hata düzeltme modeli (ECM) 4 numaralı denklem tarafindan tanımlanmaktadır:

$$
\triangle G D P P C=\alpha_{0}+\sum_{i=1}^{q} \phi_{i t} \Delta G D P P C_{i, t-i}+\sum_{i=1}^{n} \alpha_{1} \Delta K S B S H_{t-i}+\sum_{i=1}^{n} \alpha_{2} \Delta P O P_{t-i}+\alpha_{3} E C M_{t-1}+e_{t}
$$

Yukarıdaki eşitlikte $E C M_{t-1}$ olarak gösterilen değişken hata düzeltme terimini ifade etmektedir. Bu terim değişkenler arasında uzun dönem ilişkisinin elde edildiği modelin kalıntılarının bir gecikmeli değerini göstermektedir. ECM ifadesinin katsayısı kısa dönemde meydana gelen bir şokun ne kadarının bir dönemde düzeleceğini göstermektedir (Paseran, ve diğ., 2001).

\subsection{Uzun Dönem Tahmin Yöntemleri}

İçsellik sorunundan kaynaklanan problemleri gidermek için yarı-parametrik bir düzeltme kullanan tam değiştirilmiş EKK (FMOLS) tahmincisini, Philips ve Hansen (1990) geliştirmişlerdir. Klasik EKK tahmincisindeki sapmayı ve içsellik sorunlarını düzelterek tam değiştirilmiş EKK tahmincisi elde edilmektedir. FMOLS tahmin aşamaları şöyledir (Phillips ve Hansen, 1990: 101-102);

- İlk olarak açıklayıcı regresyon hataları $\left(w_{t}\right)$ ve eş bütünleşme regresyon hataları $\left(\varepsilon_{t}\right)$ EKK yöntemi kullanılarak bulunur. 
- Tek yönlü uzun dönem kovaryans matrisi $(\Lambda)$ ve kovaryans matrisi $(\Omega)$ ilk aşamadaki hata terimleri kullanılarak tahmin edilir.

- İçsellik sorununu çözmek için bağımlı değişken dönüştürülür;

$\mathrm{y}_{\mathrm{t}}^{+}=\mathrm{y}_{\mathrm{t}}-\widehat{w}_{12} \widehat{\Omega}^{-1} 22 \hat{u}_{2 \mathrm{t}}$

$\hat{u}_{2 \mathrm{t}}=\Delta \widehat{W}_{\mathrm{t}}$

$\mathrm{yt}^{+}=\mathrm{yt}-\hat{p} \Delta \mathrm{X}_{\mathrm{t}}$

$\hat{p}=\frac{\widehat{\Omega}_{21}}{\widehat{\Omega}_{22}}$

$\mathrm{yt}^{+}=\mathrm{yt}-\left(\frac{\widehat{\Omega}_{21}}{\widehat{\Omega}_{22}}\right) \Delta \mathrm{X}_{\mathrm{t}}$

$\hat{\theta}_{\mathrm{FMOLS}}=\left[\begin{array}{c}\hat{\beta} \\ \hat{y}\end{array}\right]=\left(\sum_{t=1}^{T} X_{t} y_{t}^{+}-\mathrm{T} \hat{\lambda}_{12}^{+}\right)=\left(\sum_{t=1}^{T} X_{t} y_{t}^{\prime}\right)^{-1}$

$\hat{\lambda}_{12}^{+}=\hat{\lambda}_{12}^{+}-\widehat{w}_{12} \widehat{\Omega}^{-1}{ }_{22} \Lambda_{22}$

$\hat{t}_{F M O L S}=\frac{\hat{\theta}_{F M O L S}}{\left(\hat{\Omega}_{11} \sum_{t=1}^{T} X_{t}^{2}\right)}$

Kanonik Eş bütünleşme regresyonu Park (1992) tarafından geliştirilmiştir. FMOLS tahmincisine çok benzerdir ve FMOLS tahmincisinden farkı EKK'daki içsellik ve sapmayı düzeltmek için veride $\left(Y_{t}, X_{t}\right)$ durağan dönüşümler kullanılmasıdır. CCR tahmin aşamaları aşağıdaki gibidir (Park, 1992);

- FMOLS tahmin aşamasında olduğu gibi, ilk olarak açıklayıcı regresyon hataları $\left(W_{t}\right)$ ve eş bütünleşme regresyon hataları $\left(\varepsilon_{t}\right)$ EKK yöntemi kullanılarak bulunmaktadır.

- FMOLS'da olduğu gibi tek yönlü uzun dönem kovaryans matrisi $(\Lambda)$ ve kovaryans matrisi $(\Omega)$ tahmin edilir. CCR' de ayrıca eşanlı kovaryans matrisinin $(\Sigma)$ de elde edilmesi gerekmektedir.

- İçsellik sorununu çözmek için bağımlı ve bağımsız değişkenler aşağıdaki denklemler ile dönüştürülmektedir;

$$
\begin{aligned}
& X_{t}^{*}=X_{t}-\left(\hat{\Sigma}^{-1} \hat{\Lambda}_{2}\right)^{\prime} \hat{u}_{t} \\
& y_{t}^{*}=y_{t}-\left(\hat{\Sigma}^{-1} \hat{\Lambda}_{2} \hat{\beta}_{O L S}+\left[\begin{array}{c}
0_{\left[\hat{\Omega}_{22}^{-1} \hat{\omega}_{21}\right]}
\end{array}\right]\right)^{\prime} \hat{u}_{t} \\
& \text { Bu denklemde } \hat{\Lambda}_{2}=\left[\begin{array}{c}
\Lambda_{12} \\
\Lambda_{22}
\end{array}\right] \text { eşittir. }
\end{aligned}
$$

Son olarak ise dönüştürülmüş veriye EKK uygulanarak CCR tahmincisine ulaşılmaktadır.

$$
\vartheta_{C C R}=\left[\begin{array}{l}
\hat{\beta} \\
\hat{Y}
\end{array}\right]=\left(\sum_{t=1}^{T} X_{t}^{*} y_{t}^{*}\right)\left(\sum_{t-1}^{T} X_{t}^{*} X_{t}^{*}\right)^{-1}
$$

EKK tahmincisindeki sapma ve içsellik sorununu çözmek amacıyla Stock ve Watson (1993) eşbütünleşme regresyonunun, açıklayıcı değişkenlerin gecikme (q) ve öncülleriyle genişletilmesini önermiştir. Genel bir DOLS modeli aşağıdaki gibi yazılabilir (Stock ve Watson, 1993);

$$
y_{t}=x_{1 t}^{l}+Y_{1}+\sum_{j=-q}^{r} \delta_{j} \Delta X_{t-j}+\varepsilon_{t}
$$

$\Delta X_{t}$ 'nin gecikme ve öncüllerinin DOLS modeline eklenmesiyle, eşbütünleşme regresyonu hatalarıyla açıklayıcı değişkenlerdeki inovasyonlar dikleşir ve bu sayede içsellik sorunu ve sapma ortadan kalkar.

Johansen ve FMOLS yaklaşımlarına göre DOLS yaklaşımı daha avantajlıdır. Çünkü Johansen yönteminde bir denklemdeki parametre tahmini diğer bir denklemdeki model kurma

hatasından etkilenmektedir, ancak DOLS yöntemi tek bir denklemle çalıştığı için böyle bir sorunla karşılaşılmaz. Ayrıca DOLS yönteminin kullanılabilmesi için bağımlı ve açıklayıcı değişkenler arasında eş bütünleşme ilişkisi olması gerekmektedir.

\section{Ampirik Bulgular}

Çalışmada, uygun olan optimal ARDL modelinin seçimi için tahmin, $(p+1)^{k}$ kez tekrarlanır ve bu sayede optimal modele Akaike Bilgi Kriteri (AIC) aracılı̆̆ı ile ulaşılır. Burada, $k$ değişken sayısını ve $p$ değeri de optimal gecikme uzunluğunu göstermektedir. 
Tablo. 4 Optimum Gecikme Uzunluğu Seçim Sonuçları

\begin{tabular}{|l|l|l|l|}
\hline & AIC & SIC & LM $\left(X^{2}\right)$ \\
\hline $\mathbf{1}^{*}$ & $\mathbf{1 . 6 1 2 . 3 6 7}$ & $\mathbf{1 . 6 2 9 . 9 6 2}$ & $\mathbf{0 . 4 4}$ \\
\hline 2 & 1.612 .367 & 1.629 .962 & 0.44 \\
\hline 3 & 1.612 .367 & 1.629 .962 & 0.44 \\
\hline 4 & 1.614 .770 & 1.651 .049 & 0.62 \\
\hline 5 & 1.614 .770 & 1.651 .049 & 0.62 \\
\hline 6 & 1.614 .770 & 1.651 .049 & 0.62 \\
\hline 7 & 1.580 .168 & 1.692 .264 & 0.00 \\
\hline 8 & 1.390 .217 & 1.512 .802 & 0.00 \\
\hline
\end{tabular}

Optimal gecikme uzunluğu Akaike Bilgi Kriteri (AIC) ve Breusch-Godfrey, $X^{2}$ değerlerine göre saptanmıştır. 7. ve 8. gecikmede ardışık bağımlılık tespit edildiğinden kullanılamamaktadır. Sonuçlara göre, optimum olarak 1. gecikme tespit edilmişstir.

Tablo. 5 Sinır Testi

\begin{tabular}{|l|c|c|}
\hline & ARDL Gecikme Uzunluğu & F-İstatistik, Sınır Testi \\
\hline $\begin{array}{l}\text { LnGDPPC } \\
=f(\text { LnKSBSH,LnPOP })\end{array}$ & $(1,0,0)$ & $\mathbf{5 . 0 5 8 4 * *}$ \\
\hline Anlamlllı Seviyesi & Alt Sınır & Üst Sınır \\
\hline$\% 1$ & 5.15 & 6.36 \\
\hline$\% 5$ & 3.79 & 4.85 \\
\hline$\% 10$ & 3.17 & 4.14 \\
\hline
\end{tabular}

Not :**\%5 anlamlılık düzeylerini ifade etmektedir. Ayrıca modelin tanısal testleri şu şekildedir: $R^{2}=0.963$. BreushPagan-Godfrey test sonucu 0.2644(0.9666) Değişen varyans problemi yoktur. Breush-Godfrey test sonucu 0.0895(07647) Otokorelasyon problemi yoktur. Ramsey Reset test sonucu 0.7883(0.3814) Tanimlama hatasi yoktur.

5.0584 olarak hesaplanan F-İstatistik değeri kritik değerler ile karşılaştırıldığı zaman \%5 anlamlılık seviyesinde üst sınır değerinden büyük olduğu için anlamlı kabul edilmektedir. Çıkan istatistiki sonuca göre Türkiye'de ekonomik büyüme ile bu değişkenler arasında uzun dönemde bir ilişkisi olduğu gözlemlenmektedir.

Bu noktadan sonra, uzun dönem ilişkinin varlığının ortaya konduğu bu model için uzun dönem ARDL tahmin sonuçlarına bakılmalıdır. Tablo 6' da kişi başı gayri safi yurt içi hasılanın bağımlı değişken ve kişi başı sağlık harcamaları ile 65 yaş üzeri nüfusun toplam nüfusa oranının açıklayıcı değişkenler olarak tanımlanan modelin ARDL uzun dönem sonucu gösterilmektedir.

Tablo. 6 Uzun Dönem ARDL Sonuçları

\begin{tabular}{|l|l|l|l|}
\hline Değişkenler & Katsayı & Standart Hata & t-İstatistiği \\
\hline LnKSBSH & 0.4120 & 0.1550 & $\mathbf{2 . 6 5} * *$ \\
\hline LnPOP & 1.0959 & 1.0241 & 1.070 \\
\hline C & 4.3278 & 1.0790 & $\mathbf{4 . 0 1 0 8 * * *}$ \\
\hline
\end{tabular}

Not: *, **ve ***ifadeleri sırasıyla \%10, \%5 ve \%1 anlamlılı düzeylerini ifade etmektedir. Ayrica modelin tanısal testleri şu şekildedir: $R^{2}=0.963$. Breush-Pagan-Godfrey test sonucu 0.0789(0.9710) Değişen varyansproblemi yoktur. Breush-Godfrey test sonucu 0.0773(0.7828) Otokorelasyon problemi yoktur. RamseyReset test sonucu 0.7883(0.3814) Tanımlama hatasi yoktur.

Uzun dönem tahminine göre; kişi başı yapılan sağlık harcamalarındaki \%1'lik bir artış, kişi başı gayri safi milli hasılayı \%0,412 oranında arttırmaktadır. Diğer yandan 65 yaş üzeri nüfustaki değişimin kişi başı gayri safi yurt içi hasıla üzerindeki uzun dönem etkisi anlamlı görünmemektedir.

Kişi başı sağlık harcamaları ve 65 yaş üzeri nüfus için kısa dönem ARDL sonuçları, dengeden sapma halinde bir dönemde sapmanın ne kadarının düzeltilebildiğinin gösterilmesi açısından önemlidir. 
Tablo. 7 Kisa Dönem ARDL Sonuçları

\begin{tabular}{|l|l|l|l|}
\hline Değ işkenler & Katsayı & Standart Hata & t-İstatistiği \\
\hline ALnKSBSH & 0.1512 & 0.0519 & $\mathbf{2 . 9 0 8 9 * * *}$ \\
\hline LLnPOP & 0.4023 & 0.4605 & 0.8736 \\
\hline ECT(-1) & -0.3671 & 0.1264 & $\mathbf{- 2 . 9 0 4 3 * * *}$ \\
\hline
\end{tabular}

Not: *, **ve *** ifadeleri sirasıyla \%10, \%5 ve \%1 anlamlılık düzeylerini ifade etmektedir.

Buna göre Tablo 7'de gösterilen değerler ele alınan örneklemde, kişi başı sağlık harcamaları ve yaşlı nüfus oranından kaynaklanan şokların \%36.71'i aynı dönem içerisinde giderildiğini göstermektedir. Diğer bir ifadeyle hata düzeltme mekanizması çalışmaktadır.

CUSUM testi, ilk n tane gözlemi kullanarak sürekli tekrarlanan tahminlerden elde edilen hata terimlerinin tamamının toplamları alınması şeklinde yapılan ve \%5 anlamlılık düzeyi için katsayıların istikrarını inceleyen istatistiki sonuçları göstermektedir. Gözlem sayısının en küçükten başlayarak sürekli olarak artırılması ile elde edilen bu toplam rakamın grafiğin \%5'lik anlamlılık düzeyini ifade edebilmesi için, sıfırdan başlayıp dalgalı bir şekilde devam eden çizginin sınır çizgileri içerisinde (bant içerisinde) kalması gerekmektedir. O zaman katsayıların kararlı olduğu kabul edilmektedir. Diğer yandan, hata terimlerinin karelerinin toplamına dayanan CUSUMQ testi de benzer şekilde hesaplanmaktadır.

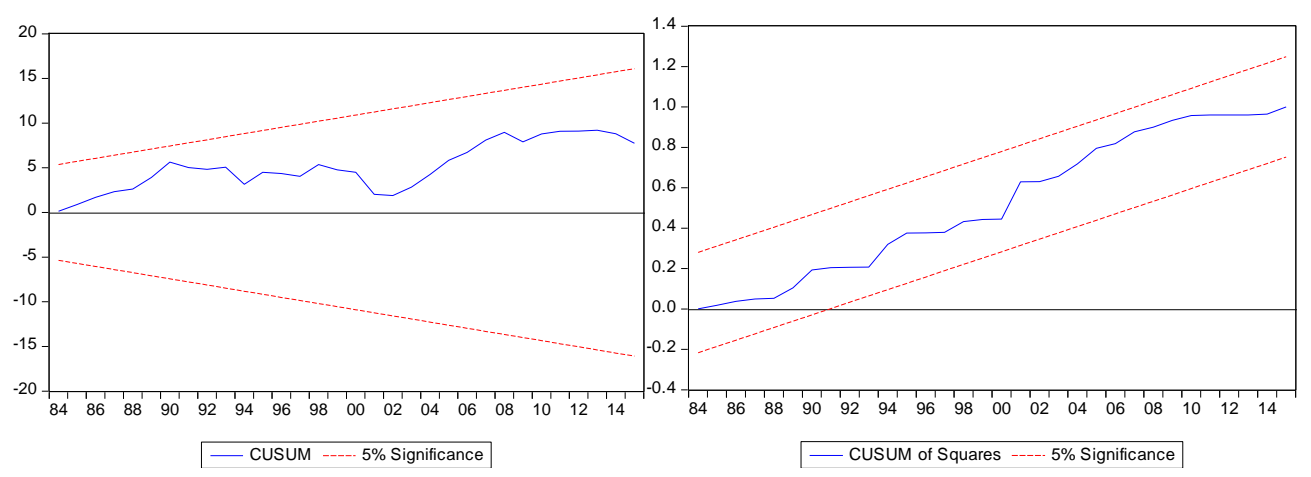

Şekil. 1 CUSUM Testi

Şekil. 2 CUSUMQ Testi

Şekil 2 CUSUM testi sonuçlarını ve Şekil 3 ise CUSUMQ testi sonuçlarını \%5 anlamlılık düzeyi için göstermektedir. Her iki şekle bakıldığında bant içerisinde kalan tahmini katsayı değerleri,bu modelin zaman içinde kararlılık gösterdiğini ifade etmektedir.

Çalışmada her ne kadar Türkiye'de sağlık yönlü büyüme modelinin geçerli olduğu ARDL yöntemi ile gösterilmiş olsa da, modelde kullanılan tüm serilerin farkta durağan olmasından dolayı FMOLS, CCR ve DOLS yöntemleriyle de bir sınama yapılabileceği düşünülmüştür. Bu modeller kullanılarak elde edilen tahmin sonuçları Tablo 8'de ifade edilmektedir.

Tablo. 8 FMOLS, CCR ve DOLS Sonuçları

\begin{tabular}{|c|c|c|c|}
\hline Değişkenler & FMOLS & CCR & DOLS \\
\hline$\Delta$ LnKSBSH & $\begin{array}{l}02686 \\
(0.0093)^{* * * *}\end{array}$ & $\begin{array}{l}0.2582 \\
(0.0058)^{* * * *}\end{array}$ & $\begin{array}{l}0.4129 \\
(0.0045 * * *\end{array}$ \\
\hline$\Delta \ln P O P$ & $\begin{array}{l}1.9595 \\
(0.0060) * * *\end{array}$ & $\begin{array}{l}2.0349 \\
(0.0004)^{* * * *}\end{array}$ & $\begin{array}{l}.1716 \\
(0.1527)\end{array}$ \\
\hline C & $\begin{array}{l}3.5083 \\
(0.0000)^{* * * *}\end{array}$ & $\begin{array}{l}3.4328 \\
(0.0000)^{* * *}\end{array}$ & $\begin{array}{l}4.2404 \\
(0.0000)^{* * * *}\end{array}$ \\
\hline
\end{tabular}

Not: *, **ve *** ifadeleri strasıyla \%10, \%5 ve\%1 anlamlllı düzeylerini ifade etmektedir.

Sonuç olarak, elde edilen bulgular genel itibari ile Türkiye'de kişi başı sağlık harcamalarının ekonomik büyümeyi olumlu yönde etkilediğini ortaya koymaktadır. FMOLS ve CCR tahmin sonuçlarının birbirine benzer çıkması, tahmin edilen katsayı değerlerinin doğru bir şekilde yorumlama olanağı sunmaktadır. Ancak ARDL ve DOLS sonuçlarının birbirine benzer çıkması uzun dönem ilişkinin ortaya konması bakımından kayda değerdir. Buna göre, FMOLS tahminleri, kişi başı sağlık harcamalarındaki \%1'lik artışın kişi başı geliri \%0.27 oranında 
artırdığını, 65 yaş üstü nüfusun toplam nüfusa oranındaki \%1'lik artışın ise kişi başı geliri yaklaşık olarak \%2 artırdığını göstermektedir. CCR tahminleri, kişi başı sağlık harcamalarındaki \%1'lik artışın kişi başı geliri \%0.26 artırdığını, 65 yaş üstü nüfusun toplam nüfusa oranındaki \%1'lik artışın ise kişi başı geliri yaklaşık olarak \%2 artırdığını belirtmektedir. Son olarak DOLS tahminleri ise, kişi başı sağlık harcamalarındaki \%1'lik artışın, kişi başı geliri \%0.41 artırdığını, 65 yaş üstü nüfusun toplam nüfusa oranının ise istatiksel olarak anlamlı bir sonuç üretmediğini ortaya koymaktadır. Bu noktada özellikle DOLS ve ARDL sonuçlarının benzerliği dikkat çekicidir.

Çalışmanın sonuçlarını, Türkiye üzerine yapılan diğer çalışmalar ve Avrupa Birliği ile Türkiye'nin birlikte ele alındığı çalışmaların bulguları ile karşılaştırmak mümkündür. Bu anlamda, Atılgan ve diğg. (2016) yaptığ çalışmada 1975-2013 dönemlerine ait yıllık veriler ile Türkiye'de sağlık temelli büyümenin varlığını araştırmıştır. ARDL eş bütünleşme analizi sonucunda elde edilen bulgular kişi başına düşen sağlık harcamalarında \% 1'lik bir artışın kişi başına düşen gayri safi yurt içi hasılada \% 0.434'lük bir artış sağlayacağını göstermiştir. Bu sonuç, çalışmamızda elde edilen sonuca oldukça benzer görülmektedir. Bu anlamda, her iki çalışmada da sağlık harcamalarının uzun dönemde ekonomik büyümeyi pozitif yönlü etkilediği açıkça görülebilmektedir. Diğer yandan, kullanılan yöntemin aynı olmasına karşın Şimşir ve diğ. (2015) 1975-2012 dönemlerine ait yıllık veriler ile yaptıkları çalışmada Türkiye'de sağlık harcamalarının ekonomik büyümeye etkisini uzun ve kısa dönemler için araştırmıştır. Buna göre, elde edilen katsayı değerleri uzun dönemde toplam sağlık harcamalarının GSYH içerisindeki payı, bin kişiye isabet eden kaba ölüm oranı ve doktor sayısı \%1 arttığında ekonomik büyüme sırasıyla $\% 0.07, \% 1.79$ ve 0.97 oranında azalmaktadır. Öte yandan, cari kısa dönemdeki toplam sağlık harcamalarının GSYH içindeki payı arttığında ekonomik büyüme \%1.20 azalırken, bir dönem gecikmesi alındığında \%1.77 artmakta, iki dönem gecikmesi alındığında ise \%3 azalmaktadır. Ay, Kızılkaya ve Koçak (2013) Türkiye için yaptıkları çalışmada 1968-2006 yıllarına ait reel GSYH, yataklı sağlık kurumu sayısı, sağlık memuru başına düşen kişi sayısı ve yataksız sağlık kurumu sayısı serilerini kullanarak uzun dönemde sağlık göstergelerinin ekonomik büyüme üzerine etkisini araştırmışlardır. Buna göre, Yataklı sağlık kurumu sayısındaki \% 1'lik artış, GSYİH'da \% 13,213'lük bir artış1, yataksız sağlık kurumu sayısındaki \% 1'lik artış, GSYİH'da \% 0,787'lik bir artış1 ve sağlık memuru başına düşen kişi sayısındaki \% 1'lik bir artış, GSYİH'da \%5,602'lik bir artışı desteklemektedir. Bu sonuçlar sağlık harcamalarının uzun dönemde ekonomik büyümeye katkısının pozitif yönlü olduğunu göstermektedir. Türkiye'de sağlık harcamaları, sağlık harcamalarının nisbi fiyatı ve ekonomik büyüme arasındaki ilişkiyi inceleyen Akar (2014), Ocak 2004 - Mart 2013 dönemine ait veri seti ile yaptığ çalışmada, uzun dönemde sağlık harcamalarının, bu harcamaların nisbi fiyatı ve ekonomik büyüme arasında anlamlı bir ilişki tespit ederken, kısa dönemde anlamlı bir ilişki tespit edememiştir. Buna göre, 2005-2008 sağlık harcamalarının GSYH içindeki payı pozitif eğimliyken, 2008-2009 yıllarında küresel krizin etkisiyle sabit bir düzeyde (\%6.1) seyrettiğini belirtmiştir. Devam eden yıllarda krizin etkilerinin azalması ile artış trendinin yavaş da olsa sağlanmış olması, 2010, 2011, ve 2012 yıllarında sırasıyla 5.6, 5.3 ve 5.4 oranlarında gerçekleştiğini ortaya koymuştur. Son olarak Selim ve diğ. (2014) yapmış oldukları çalışmada 2001-2011 yılları için 27 Avrupa ülkesi ve Türkiye’yi kapsayan ekonomik büyüme ile kişi başı sağlık harcamalarının uzun ve kısa dönemdeki ilişkilerini panel eş bütünleşme testi ile araştırmışlardır. Fakat bu çalışmada, diğer çalışmalardan farklı olarak literatürde ilk defa uzun ve kısa dönem ilişkiler hata düzeltme modeli çerçevesinde ele alınmıştır. Elde edilen bulgulara göre, bu iki değişken arasındaki ilişki uzun ve kısa dönemde pozitif olmasının yanı sıra, kısa dönemdeki sapmaların \%58 'inin aynı dönem içersinde giderilebiliceğini göstermiştir. Çalışmada, Avrupa Birliği’ne girme sürecinde olan Türkiye'nin sağlık harcamaları konusunda birlik ülkelerinin gerisinde kaldığı ve bunun da gelişmesi üzerinde büyük bir engel olduğu vurgulanmıştır.

\section{Sonuç ve Politika Çıkarımları}

Bu çalışmada amaç, 1979-2015 döneminde Türkiye'de ekonomik büyüme ve kişi başı sağlık harcamaları arasındaki kısa ve uzun dönemli ilişkinin varlığını ölçmektir. Çalışmada, literatürde bulunan büyüme - sağlık harcaması ilişkisini inceleyen diğer çalışmalarda kullanılan açıklayıcı değişkenlerden farklı olarak 65 yaş üzeri nüfusun toplam nüfusa oranı değişkeni kullanılmıştır. Burada yaşlı nüfusun değişken olarak kullanılmasının sebebi toplumdaki en çok sağlık harcaması yapan grubu temsil etmesidir. Elde edilen bulgular uzun dönemde kişi başı sağlık harcamalarındaki \%1'lik bir artışın, kiși başı gayri safi milli hasılayı \%0,412 oranında arttırdığını, diğer yandan 65 yaş üzeri nüfustaki değişimin kişi başı gayri safi yurt içi hasılayı etkilemediğini göstermiştir. Aynı zamanda çalışmada kısa dönem ilişkileri de hata düzeltme modeli kullanılarak analiz edilmeye çalışılmıştır. Buna göre, kısa dönemde kişi başı sağlık harcamaları ve yaşlı nüfus oranından kaynaklanan şokların \%36.71'i aynı dönem içerisinde giderilebildiği ve böylece hata düzeltme mekanizmasının çalıştığı görülmüştür. Diğer bir ifadeyle hata düzeltme terimi (ECT) istatistikî olarak anlamlıdır ve beklendiği gibi negatiftir. Bu anlamda, uzun dönemde, birlikte hareket eden seriler arasında kısa dönemde meydana gelen sapmalar ortadan kalkmakta ve seriler tekrar uzun dönem denge değerine yakınsamaktadır.

Çalışmada, ARDL yöntemiyle elde edilen tahmini sonuçları, diğer bazı ekonometrik yöntemlerle (CCR, DOLS ve FMOLS) de elde edilmeye çalışılmıştır. Buna göre, FMOLS ve CCR tahmincileri, kişi başı sağlık harcamalarında \%1'lik bir artışın hasılayı olumlu etkilediği öte yandan yaşlı nüfustaki \%1'lik artışın da hasılaya pozitif etki ettiğini göstermiştir. 
Kişi başı gayrisafi yurt içi hasıla ile 65 yaş üzeri nüfusun arasındaki pozitif ilişkinin nedenlerinden biri nüfus yapısının giderek yaşlanması ve bunun kişi başı sağlık harcamalarını artırması olabilir. Bu anlamda, devletin yapacağı sağlık yatırımlarını artırması, harcama - yatırım mekanizması oluşturacağından ekonomik büyümeye dolaylı yönden olumlu bir katkı sağlayacağı düşünülmektedir. Bu bağlamda, sağlık hizmetlerinin yeterliliğini belirleyebilmek amacıyla ilgili kurumların bölgesel ve ulusal çalışmalar yapmaları ve bunun sonucunda gerekli sağlık politikalarının neler olacağına karar vermeleri gerekmektedir.

Toplumun eğitim seviyesinin yükselmesi sağlık bilincini de artıracağından hizmet beklentisi yükselmektedir. Eğitim düzeyinin yüksek olan toplumlarda, sağlığa önem verildiği ve bireylerin bu alanda yapılan gerek bilimsel çalışmaları gerekse teknolojik adımları yakından takip ettiği bilinmektedir. Bu anlamda, ilgili kurumlar tarafından sağlık sektöründe yaşanan gelişmeleri yurt içinde ve yurtdışında yakinen takip etmesi zorunluluk olarak görülmelidir. Bunun yanında ülke içerisinde tıp alanında yapılan çalışmalara daha fazla teşvik verilmesi, gerek AR-GE gerekse eğitime yapılan harcamaların dolaylı yoldan sağlığı etkileyeceği düşünülerek yeni politika hedefleri buna göre belirlenmelidir. 


\section{KAYNAKÇA}

Atılgan, E., K1lıc, D., \& Ertugrul, H. (2017). The Dynamic Relationship Between Health Expenditure and Economic Growth: Is The Health Led-Growth Hypothesis Valid for Turkey. The European Journal of Health Economics , 567-574.

Akar, S. (2014). Türkiye'de Sağlık Harcamaları, Sağlık Harcamalarının Nisbi Fiyatı ve Ekonomik Büyüme Arasındaki İlişkinin İncelenmesi. Yönetim ve Ekonomi, 311-322.

Ay, A., Kızılkaya, O., \& Koçak, E. (2013). Sağlık Göstergeleri ile Ekonomik Büyüme Arasındaki İlişki: Türkiye Örneği. Ömer Halisdemir Üniversitesi İktisadi ve İdari Bilimler Fakültesi Dergisi , 163-172.

Aydemir, C., \& Baylan, S. (2015). Sağllk Harcamalarl ve Ekonomik Büyüme Illişkisi: Türkiye Üzerine Bir Uygulama. Dicle Üniversitesi Sosyal Bilimler Enstitüsü Dergisi , 417-435.

Bakare, A., \& Olubokun, S. (2011). Health Care Expenditure and Economic Growth in Nigeria: An Empirical Study. Journal of Emerging Trends in Economics and Management Sciences, 83-87.

Barro, R. (1991). Economic Growth in a Cross Section of Countries. The Quarterly Journal of Economics , $407-$ 443.

Barro, R. (1996). Three models of health and economic growth, Unpublished Manuscript,Cambridge, MA: Harvard University.

Becker, G.S., K.M. Murphy ve R. Tamura, 1990, .Human Capital, FertilityandEconomicGrowth,. Journal of PoliticalEconomy98:5 (October), 12-37.

Bloom, D.E., Canning, D., Sevilla, J. (2001). The Effect of Health on Economic Growth:Theory and Evidence, National Bureau of Economic Research Working Paper, no. 8587.

Çalışkan, Ş., Karabacak, M., \& Meçik, O. (2013). Türkiye'de Sağllk-Ekonomik Büyüme İlişkisi. Dumlupınar Üniversitesi Sosyal Bilimler Dergisi , 123-130.

Çetin, M., \& Ecevit, E. (2010). Sağllk Harcamalarının Ekonomik Büyüme Üzerindeki Etkisi: OECD Ülkeleri Üzerine Bir Panel Regresyon Analizi. Doğuş Üniversitesi Dergisi , 166-182.

Çoban, O. (2003). Eğitim, Beşeri Sermaye ve İktisadi Büyüme Etkileşimi Türkiye Üzerinde

Ekonometrik Bir Inceleme 1980-1997. II. Ulusal Bilgi, Ekonomi ve Yönetim Kongresi Bildirimler Kitab1 (s. 171-180). içinde Derbent-İzmir.

Engle, Robert F. and Clive W. J. Granger, (1987): "Co-Integration and Error Correction: Represention, Estimation and Testing”, Econometrica, 55(2): 251 - 276.

Ercan, N. Y. (2000). İçsel Büyüme Teorisi: Genel Bir Bakış. DPT- Planlama Dergisi , 129-138.

Fuller, D., \& Fuller, W. A. (1981). Likelihood Ratio Statictics for Autoregressive Time Series with a Unit Root. Econometrica , 1057-1072.

Gerdtham, U.-G., \& Löthgren, M. (2000). On stationarity and cointegration of international health expenditure and GDP. Journal of Health Economics , 461-475.

Hayaloğlu, P., \& Bal, H. Ç. (2015). Üst Orta Gelirli Ülkelerde Sağlık Harcamaları ve Ekonomik Büyüme. İşletme ve İktisat Çalışma Dergisi , 35-44.

Inuwa, N., \& Usman, H. M. (2012). Health Expenditure And Economic Growth Nexsus: An ARDL Approach For The Case of Nigeria. JORIND .

Jaoul, M. (2004). Higher education, causality and Growth: A Comparison of France and Germany Before the Second World War. Compare , 117-133.

Johansen, Soren (1988): "Statistical Analysis of Cointegration Vectors", Journal of Economic Dynamic and Control(12), 231-254.

Keskin, A. (2011). Ekonomik Kalkınmada Beşeri Sermayenin Rolü ve Türkiye. Atatürk Üniversitesi İktisadi İdari Bilimler Dergisi , 125-153.

Lucas, R. (tarih yok). On the Mechanics of Economic Development. Journal of Monetary Economics , 3-42.

Lustig, M. (2006). Investing in Health for Economic Development: The Case of Mexico. Working Paper Series, . World İnstute for Development Economic Research (UNU-WIDER), 30.

Mankiw, G. N. (1992). A Contribution to The Empirics of Economic Growth. Quarterly Journal of Economics, $107,407-437$.

Mehmood, B., Raza, S. H., \& Mureed, S. (2014). Health Expenditure, Literacy and Economic Growth: PMG Evidence from Asian Countries. Euro-Asian Journal of Economics and Finance , 408-417.

Park, J. Y. (1992). Canonical Cointegrating Regressions. Econometrica , 119-143.

Peseran, M. Hashem, Shin Yongcheol and Smith Richard; (2001), "Bound Testing Approaches to the Analysis of Level Reletionships", Journal of Applied Econometrics 16, pp. 289-326.

Phillps, P. B., \& Hansen, B. E. (1990). Statistical Inference in Instrumental Variables Regression with I(1) Processes. Cowles Foundation for Research in Economics, Yale University , 99-125.

Romer, P.M., 1994, .The Origins of Endogenous Growth,. The Journal of Economic Perspectives 8:1 (January), 3-22

Selim, S., Uysal, D., \& Eryiğit, P. (2014). Türkiye'de Sağlık Harcamalarının Ekonomik Büyüme Üzerindeki Etkisinin Ekonometrik Analizi . Niğde Üniversitesi İktisadi ve İdari Bilimler Fakültesi Dergisi , 13-24. 
Kızıl, B., C., Ceylan, R. Journal of Yasar University, 2018, 13/50, 197-209

Stock, J. H., \& Watson, M. W. (1993). A Simple Estimator of Cointegrating Vectors in Higher Order Integrated Systems. Econometrica , 783-820.

Şimşir, N. C., Çondur, F., Bölükbaş, M., \& Alataş, S. (2015). Türkiye'de Sağlık ve Ekonomik Büyüme İlişkisi:ARDL Sınır Testi Yaklaşımı. Finans Politik \& Ekonomik Yorumlar , 43-54.

Taban, S. (2006). Türkiye'de Sağllk ve Ekonomik Büyüme Arasındaki Nedensellik Illişkisi. Sosyoekonomi , 32-46.

Vasudeva, M. N., \& Okunade, A. A. (2016). Determinants of U.S. Health Expenditure: Evidence From Autoregressive Distributed Lag (ARDL) Approach to Cointegration. Economic Modelling, 67-73.

Yanıkkaya, H. (2002). Beşeri Sermaye Birikiminin Ekonomik Büyüme Sürecindeki Rolü Üzerine Amprik Bir Çalışma . İstatistik Araştırma Dergisi .

Yardımcıoğlu, F. (2012). OECD Ülkelerinde Sağlık ve Ekonomik Büyüme İlişkisinin Ekonometrik Bir Incelemesi. Eskişehir Osmangazi Sosyal Bilimler Dergisi , 27-47.

Yumuşak, İ., \& Yıldırım, D. Ç. (2009). Să̆lık Harcamaları İktisadi Büyüme İlişkisi Üzerine Ekonometrik Bir Makale. The Journal of Knowledge \& Knowledge Management , 57-70. 